\title{
Excursions
}

Volume 10, Issue 1 (2020) | Chaos

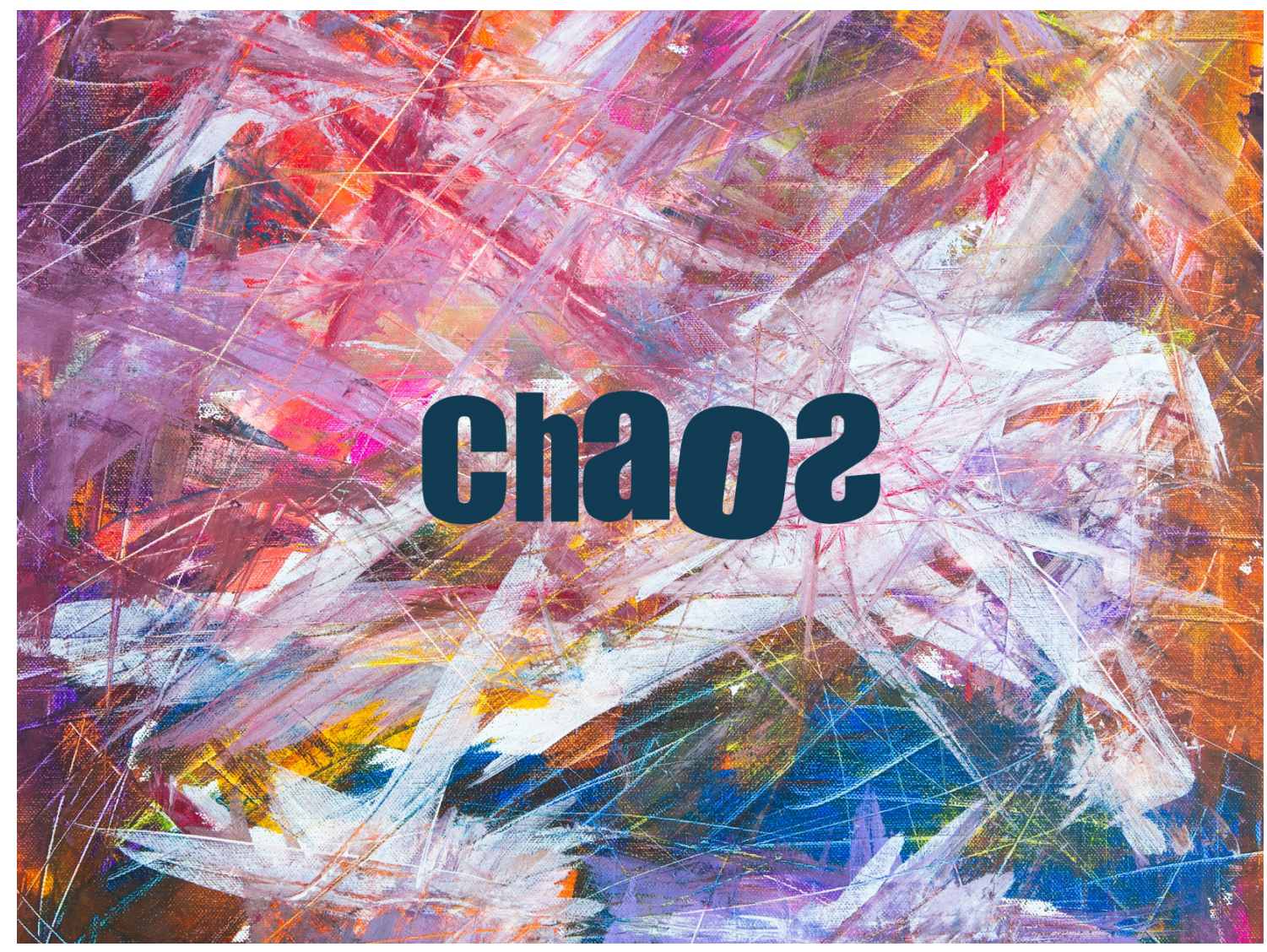

Cover photo: Unbennant \#3 by Felix Spiske | Photo by Markus Spiske on Unsplash

Essays: Research in Times of Chaos

\author{
Aizuddin Mohamed Anuar \\ Staying with the (Research) Trouble
}




\section{Staying with the (Research) Trouble}

\section{Aizuddin Mohamed Anuar \\ University of Oxford}

There are times when I feel like I am reliving the same day over and over. At my family home in the interior of Peninsular Malaysia, I pace indoors, coated by the punishing midday heat. Observing lockdown for more than two months now - my PhD fieldwork at a rural school 4 hours away disrupted - I am slowly forgetting the contours of life beyond this house.

I attempt to engage in the life of the mind somehow amidst the chaos. The writing of fieldnotes continue, however sparse and ambivalent they may be in this time (am I technically in the field?). Slowly, through challenging and hazy days of writing, draft manuscripts for a journal article and book chapter are birthed. This PhD continues, I convince myself, even when I do not feel up for it on certain days, lying motionless in bed, even when progress appears glacial, even when it seems like such an inconsequential project when the world seems to collapse...

Over these past months, I have reluctantly revised my application for institutional ethical clearance to transfer data collection into the online realm. But I am learning that to pause at this moment, to not rush into troubleshooting, to hold space for how my informants are adjusting to the circumstances of lockdown, is an act of care, an ethics transcending bureaucracy. I choose to wait things out, "staying with the trouble" in the words of Donna Haraway. In retrospect and introspect, I allowed myself time to mourn the loss of my original research design and all the aspirations

(C) Aizuddin Mohamed Anuar, 2020. License (open-access): This is an open-access article distributed under the terms of the Creative Commons Attribution License, which permits unrestricted use, distribution, and reproduction in any medium, provided the original work is properly cited. No warranty, express or implied, is given. Nor is any representation made that the contents will be complete or accurate or up to date. The publisher shall not be liable for any actions, claims, proceedings, demand or costs or damages whatsoever or howsoever caused arising directly or indirectly in connection with or arising out of the use of this material. 
infused therein. No doubt the pandemic disrupts the currents of the field, altering the course of work within it. How can it not? A friend and fellow $\mathrm{PhD}$ student, M, assuages me: "It is time to have patience and tranquillity, as our research is not disconnected to social flows... and that includes this pandemic."

I enact the tentative act of hoping as part of research. The dust will settle eventually, the world remade anew. Recently, Mr. Y who sits next to me in the teachers' room, who generously shares bread and stories with me, called to inform me that my car tyres have gone flat due to immobility. In mid-March, assuming I would return after the one-week school break, I had left the car (borrowed from my mother) and other possessions at the site. This was before lockdown became the norm; one week has stretched into ten, and counting. Despite the circumstances, relations and objects tether me, however tenuously, to the field - I latch on tightly like a child. This gives me hope of returning there eventually, even if only to say goodbye to all the informants who have taught me so much in the course of this research. At the time of writing, the Malaysian government has announced that schools will begin to reopen in two weeks. Hope, I remind myself, again and again, hope! 